NASA CR-182, 150

N $88-25459$

NASA Contractor Report 182150

NASA-CR-182150

19880016075

\title{
Two-Dimensional Viscous Flow Computations of Hypersonic Scramjet Nozzle Flowfields at Design and Off Design Conditions
}

G.J. Harloff, H.T. Lai, and E.S. Nelson

Sverdrup Technology, Inc.

(Lewis Research Center Group)

NASA Lewis Research Center

Cleveland, Ohio

June 1988

Prepared for

Lewis Research Center

Under Grant NAS3-25266

\section{NASก \\ National Aeronautics and \\ Space Administration}


TWO-DIMENSIONAL VISCOUS FLOW COMPUTATIONS OF

HYPERSONIC SCRAMJET NOZZLE FLOWFIELDS AT DESIGN AND OFF-DESIGN CONDITIONS

\author{
G.J. Harloff*, H.T. Lai"*, and E.S. Nelson***
}

Sverdrup Technology, Inc. (Lewis Research Center Group)

NASA Lewis Research Center

Cleveland, Ohio 44135

\section{Abstract}

The PARC2D code has been selected to analyze the flowfields of a representative hypersonic scramjet nozzle over a range of flight conditions from Mach 3 to 20. The flowfields, wall pressures, wall skin friction values, heat transfer values and overall nozzle performance are presented.

Nomenclature

a $=$ sound speed

$C_{f}=$ skin friction coefficient $=C_{f}=\frac{\left(\mu_{t}+\mu_{t}\right) \frac{\partial u}{\partial u}}{\frac{1}{2} p_{t} a_{s}^{2}}$

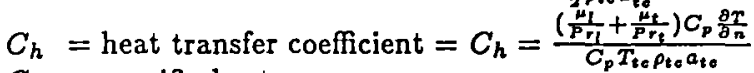

$C_{p}=$ specific heat

$C_{v}=$ velocity coefficient

$\eta \quad=$ nozzle efficiency $=\eta=\frac{h_{t c}-h_{c}}{h_{t e}-h_{t .}}$

$\gamma=$ ratio of specific heats

$\mathrm{h}=$ enthalpy

$\mathrm{M}=$ Mach number

$\mu \quad=$ viscosity

$\mathrm{n} \quad=$ unit normal

$P_{w}=$ wall pressure, $p_{w} / p_{c}$

$P_{r}=$ Prandlt number

$R_{e}=$ Reynolds number

$\rho=$ density

$\mathrm{T}=$ temperature

$\mathrm{X}$ = streamwise distance

\section{Subscripts}

c $=$ combustor exit

e $\quad$ nozzle exit

1 = laminar

- $=$ freestream condition

s $=$ constant entropy

$\mathrm{t}=$ total condition, turbulent

$\mathrm{w}=$ wall

\footnotetext{
* Supervisor, Hypersonics Analysis Section, Senior Member AIAA

** Senior Research Engineer, Hypersonics Analysis Section, Member AIAA

*** Research Engineer, Hypersonics Analysis Section, Member AIAA
}

\section{Introduction}

Accurate evaluation of nozzle performance is essential in hypersonic propulsion due to the high sensitivity of net thrust to nozzle performance. The nozzle may be highly integrated with the airframe so that the upper wall of the nozzle is actually the aft end of the airframe. The lower wall can be cut shorter than the upper wall to save weight. Examples of these types of nozzles have been given by Lewis et. al. ${ }^{1}$, and Lilly ${ }^{2,3}$.

An existing computer code, PARC2D ${ }^{4}$, is selected for this study. The code solves the full two-dimensional Reynolds averaged Navier-Stokes equations in strong conservation form with the Beam and Warming approximate factorization algorithm. The implicit scheme uses central differencing for a curvilinear set of coordinates. The code was originally developed as AIR3D by Pulliam and Steger ${ }^{5}$, and Pulliam ${ }^{6}$ later added the Jameson ${ }^{7}$ artificial dissipation and called the code ARC3D. Cooper ${ }^{4}$ adapted the code for internal propulsion and called the code PARC. The current study was conducted in 2-D and could have been conducted in 3-D with an increase in computer resources required. Previous configurations examined at NASA Lewis by Reddy and Harloff ${ }^{8}$ include: 1) a 2-D and a 3-D hypersonic nozzle at $\mathrm{M}_{0}=5$, comparisons were made with computations of Spradley ${ }^{9}$ and others; 2) a 2-D ramp at $M_{0}=14.1$ with ramp angle of $18^{\circ}$, Holden ${ }^{10}$; and 3) a 3-D corner flow configuration at $\mathrm{M}_{0}=2.94$ of Oskam et. al. ${ }^{11}$. The study by Reddy and Harloff ${ }^{8}$ provided confidence in the PARC codes for a variety of complex shapes and high speeds. Also Cooper ${ }^{12}$, obtained reasonable flowfields with PARC2D for trumpet and conical nozzles.

The goal of the current study is to examine the flowfields and overall nozzle performance over a wide range of flight conditions. There are no available experimental data, with external flow, to compare with the present computational results.

\section{Nozzle Geometry}

Figure 1 shows the nozzle geometry used in this study. The initial divergence angle is about $37^{\circ}$. The geometry was obtained from McFarland ${ }^{13}$. 


\section{Freestream and Combustor Exit Properties}

The ratio of specific heats, gamma, and the gas constant of the combustor exit are considered constant throughout the entire flowfield and the values are shown in Table 1. The static nozzle entrance Reynolds numbers, based on nozzle entrance height, are such that turbulent flow is expected for the entire Mach number range studied and turbulent flow is assumed. The freestream and combustor exit properties were obtained from McFarland ${ }^{13}$.

\section{Grid}

The grid used for the computations was $199 \times 129$, uniform in the $\mathrm{X}$ direction, see Figure 2. Grid clustering near the upper and lower walls is needed to resolve the boundary layers. Also grid clustering downstream of the cowl is needed to resolve the shear layer. The present study did not adapt the grid to the shear layer location, although this has been accomplished by the authors in previous unpublished studies. The solutions obtained with adapted grids were not significantly different.

The boundary conditions are uniform inflow and extrapolated outflow properties for supersonic flow. The supersonic/hypersonic inflow boundary above the exit was assumed to be uniform. For subsonic outflow the pressure is imposed by the sublayer approximation. These boundary conditions are ideal and more realistic inflow profiles can be accounted for. The wall temperature is assumed to be constant at $1750 \mathrm{deg} R$.

\section{Mach 3 Flowfield}

The velocity vectors at $M_{0}=3$ are shown in Figure 3. The flow is overexpanded and a shock propagates from the cowl lip to the upper nozzle wall. The exhaust flows along the upper nozzle wall similar to a wall jet. A slight separation occurs on the upper wall ahead of the shock. This is difficult to see in this figure, and it will be further discussed below. The Mach number contours are shown in Figure 4. Due to the overexpanded nature of the flow at the end of the lower cowl, the shear layer turns upward. The shear-layer deflection and pressure imbalance cause a shock to form above the shear layer.

The total pressure contours are shown in Figure 5. The gradient in nozzle and freestream total pressure across the shear layer is illustrated. As mentioned previously, the shear layer deflects upward due to the overexpansion of the nozzle flow at the cowl exit.

The divergence of velocity provides a scalar representation of density gradients such that compressive and expansive regions of the flow can be visualized. Compression regions are dark and expansion regions are light. The shock from the end of the cowl to the upper nozzle wall is illustrated in Figure 6 as a dark region. The shock deflection angle is about $39^{\circ}$ and the Mach number in front of the oblique shock is about 3.5. The shock reflects off the boundary layer and then propagates in the downstream direction, i.e. left to right. The boundary layer separates on the upper nozzle wall ahead of the incident shock. As the shock interacts with the wall boundary layer the shock initially reflects at a sharp angle. As the flow moves over the separation bubble, the flow turnes less, as shown by the decrease in magnitude of the dark-colored compression region. At the aft end of the separation bubble, the flow is again turned at a sharp angle into the reflected shock downstream of the separation. In the lower region of the flowfield, below the cowl, a shock emanating from the leading edge of the cowl is observed. This shock is caused by flow deflection due to the boundary layer development along the lower cowl wall. The expanding region of the flow downstream of the cowl is observed in the Figure 6 as a light region.

The wall pressures for the three nozzle wall surfaces, see Figure 7-a, initially decrease with increasing $\mathrm{X}$ for both upper and lower nozzle walls. The interior nozzle shock hits the upper nozzle wall at about 2.8 feet as indicated by in the marked pressure rise at this location. This feature has been shown in previous figures. The pressure below the cowl is larger than the pressure in the nozzle and this pressure difference at the end of the cowl causes the shock to form in the nozzle. The wall skin friction values are shown in Figure 7-b for the three surfaces. The skin friction on the upper nozzle wall goes negative at a location of about $2.8 \mathrm{ft}$ indicating a small region of reverse flow. The skin friction of the upper cowl wall is slightly higher than that of the upper wall, and is also higher than the skin friction of the lower cowl wall. The heat transfer for the upper and lower nozzle walls are similar in magnitude over the length of the cowl, see Figure 7-c. A slight decrease, then a rise in the heat transfer coefficient is observed near $\mathrm{X}=2.8 \mathrm{ft}$. where the boundary layer flow separates. In the nozzle, the heat transfer is positive indicating hot gas and cold wall. Below the cowl the heat transfer coefficient is negative indicating cold gas and hot wall.

\section{Mach 6 Flowfield}

The velocity vectors at Mach 6 are shown in Figure 8 . The flow is slightly overexpanded at the cowl exit and the flow expands behind the cowl by means of an expansion fan. The wake is deflected upward as is indicated by the velocity vector angles and the position of the shear layer. Reverse flow at the upper boundary is not indicated. The Mach number contours for the flowfield, shown in Figure 9, also illustrates the location of the shear layer. The total pressure contours, see Figure 10, show the upward deflection of the shear layer. The divergence of velocity are shown in Figure 11. The dark region near the upper wall differs from that of the Mach 3 flowfield. This compression region is believed to be associated with a coalescence of the shock from the lower cowl wall and a standing oblique shock in the nozzle exit. The wall pressures are shown in Figure 12-a and the overexpansion is illustrated. The wall skin friction and heat transfer values are shown in Figure $12-b$ and $12-c$ respectively. 
Mach 10 Flowfield

The exhaust flow is underexpanded at Mach 10 as indicated by the downward deflection of the nozzle flow, see Figure 13. There are no indications of shocks inside the nozzle. A shock propagates from the lower cowl lip downward, due to the underexpansion of the nozzle flow, see the Mach contours in Figure 14. Figure 15 shows the total pressure contours at Mach 10. The downward deflection of the shear layer, is illustrated. The shock from the end of the cowl to the region below the nozzle is illustrated as a dark region below in Figure 16. The shock deflection angle is about $18^{\circ}$. The pressure is constant on the lower wall, see Figure 17-a. The $\mathrm{C}_{f}$ and $\mathrm{C}_{h}$ wall values are shown in Figure 17-b and 17-c respectively.

\section{Mach 20 Flowfield}

The velocity vectors at Mach 20 are deflected downward aft of the cowl due to the underexpansion, see Figure 18. A shock propagates downward from the lower cowl. The lower cowl leading edge shock merges with the trailing edge shock about $26 \%$ of a cowl length downstream of the cowl.

The flow along the curved upper nozzle surface turns and compresses, like flow along a curved ramp, and a curved shock forms inside the nozzle. An upwardly deflected shock behind the upper nozzle wall is evident in both Figure 18 and the Mach number contours of Figure 19. The total pressure contours in Figure 20 show the downward deflection of the shear layer. The shock from the lower side of the cowl to the region below the nozzle is illustrated in the divergence of velocity contours, see Figure 21. The shock from the leading edge of the cowl merges with the shock from the aft end of the cowl about $18 \%$ of the cowl length downstream of cowl.

An interior shock along the upper wall is evident in Figure 21. This interior shock is typical at overspeeded conditions ${ }^{14}$, i.e. when the entrance Mach number exceeds the design value. Notice that the upper wall pressure does not follow the lower nozzle wall pressure but instead increases the full length of the nozzle. The nozzle flow underexpansion is evident in Figure 22-a. The $\mathrm{C}_{f}$ and $\mathrm{C}_{p}$ values are shown in Figure 22-b and 22-c respectively.

\section{Nozzle Performance}

The adiabatic nozzle efficiency, $\eta$, is the ratio of the nonisentropic and isentropic enthalpies between the combustor exit, c, and the nozzle exit, e. The velocity coefficient, $\mathrm{C}_{v}$, is the ratio of the actual to the 1-D isentropic velocity and is the square root of the nozzle efficiency. The velocity coefficient increases with Mach number up to $\mathrm{M}_{0}$ of 10 and then decreases. For example, $C_{v}$ is 0.93 at $M_{0}$ of $3,0.98$ at $\mathrm{M}_{0}$ of $6,1.0$ at $\mathrm{M}_{0}$ of 10 and 0.94 at $\mathrm{M}_{0}$ of 20. These values might differ with chemistry accounted for. This will be checked in future research. $\underline{\text { Summary }}$

Flowfields and wall values of $\mathrm{P}_{w}, \mathrm{C}_{f}$, and $\mathrm{C}_{h}$ have been computed for a scramjet nozzle from Mach 3 to 20. Overall nozzle performance has also been computed. Matching the external pressure at the cowl exit is necessary to avoid waves in the nozzle. At Mach 3 and 6 the nozzle flow is overexpanded and shocks are inside the nozzle and the shear layer is deflected upward. At Mach 10 and 20 the nozzle flow is underexpanded and shocks are outside the nozzle and the shear layer is deflected downward. At Mach 20 a shock forms inside the nozzle along the upper wall.

\section{ACKNOWLEDGEMENT}

Prepared for the NASA Lewis Research Center under Contract NAS 3-25266 project managers B. Anderson and P. Sockol.

\section{REFERENCES}

1. Lewis, W.G.E., Herd, R.J., Herbert, M.V., "Lift Characteristics of Asymmetric Exhaust Nozzles at High Flight Speeds", J.R.A.S., Vol. 70, Nov. 1966, pp.1036-1040.

2. Lilly, J.S., Hoffman, J.D., "Performance Analysis of Scarfed Nozzles", Journal of Spacecraft and Rockets, Vol. 23, No. 1, Jan.-Feb. 1986, pp. 55-62.

3. Lilly, J.S., "Design and Optimization of Propulsion Systems Employing Scarfed Nozzles", Journal of Spacecraft and Rockets, Vol. 23, No. 6, Nov.-Dec. 1986, pp. 597-604.

4. Cooper, G.K., "The PARC Codes", A.E.D.C. Report, September 1986.

5. Pulliam, T.H. and Steger, J.L., "Implicit FiniteDifference Simulations of Three Dimensional Compressible Flow", AIAA J., Vol.18, Feb. 1980, pp. 159167.

6. Pulliam T.H., "Euler and Thin Layer Navier-Stokes Codes: ARC2D, ARC3D," Notes for Computational Fluid Dynamics User's Workshop, The University of Tennessee Space Institute, Tullahoma, Tn., UTSI Pub. E02-4005-023-84, 1984, pp. 15.1-15.85.

7. Jameson, A., and Baker, T.J., "Solution of the Euler Equations for Complex Configurations", AIAA-8301929, 1983.

8. Reddy, D.R., and Harloff, G.J., "Three-Dimensional Viscous Flow Computations of High Area Ratio Nozzles for Hypersonic Propulsion", AIAA-99-0474, 26th Aerospace Sciences Meeting, Jan. 11-14, 1988, Reno, Nevada.

9. Spradley, L.W., Anderson, P.G., and Pearson, M.L., "Computations of Three-Dimensional Nozzle-Exhaust Flow Fields with the GIM Coden, NASA CR-3042, 1978. 
10. Holden, M.S., Moselle, J.R., "Theoretical and Experimental Studies of the Shock Wave-Boundary Layer Interactions on Compression Surfaces in Hypersonic Flow", CAL Report No. AF- 24100-A-1, Oct. 1969.

11. Oskam, B,Vas, I.E., and Bogdonoff, S.M., "Oblique. Shock Wave/Turbulent Boundary Layer Interactions in Three Dimensions at Mach 3, Part I, AFFDL-TR76-48, Part I, June 1976.
12. Cooper, G.K. , Jordan, J.L., and Phares, W.J., "Analysis Tool for Application to Ground Testing of Highly Underexpanded Nozzles", AIAA 87-2015.

13. McFarland, E.R., Private discussions, May 1987.

14. Nickerson, G., Private discussions, March 22, 1988.

Table 1. Freestream and Combustor Exit Properties.

\begin{tabular}{cccccccc}
$M_{0}$ & $\begin{array}{c}T_{0} \\
R\end{array}$ & $\begin{array}{c}P_{0} \\
P S I A\end{array}$ & $M_{C}$ & $T_{C}$ & $P_{C}$ & $\gamma$ & $R$ \\
& & $R S I A$ & & $F-L B / R-L B$ \\
\hline 3 & 390 & 1.7 & 1.0 & 4075 & 11.9 & 1.25 & 62.7 \\
6 & 393 & .4 & 1.5 & 4220 & 10.4 & 1.19 & 63.4 \\
10 & 409 & .15 & 1.9 & 5403 & 75.0 & 1.16 & 66.0 \\
20 & 468 & .03 & 4.6 & 5119 & 25.9 & 1.18 & 88.0
\end{tabular}

NOZZLE DEFINITION

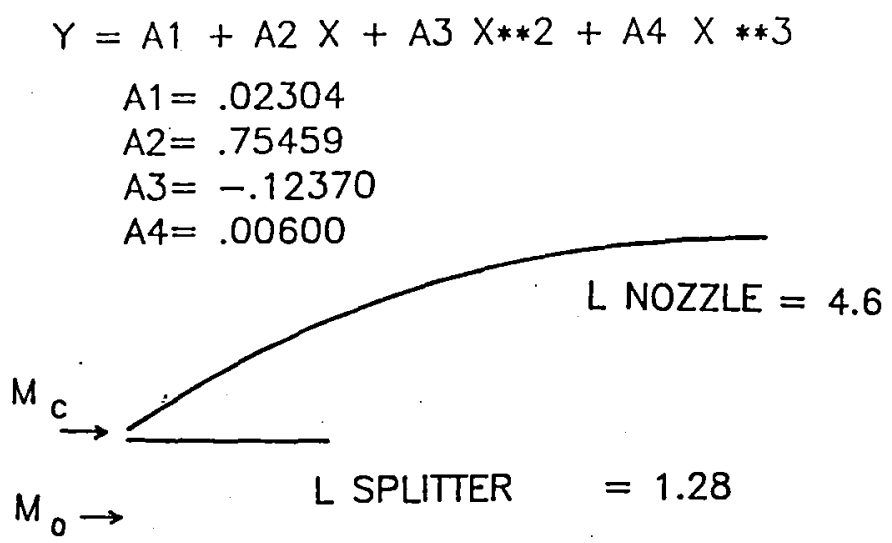

Figure 1. Nozzle Definition. 


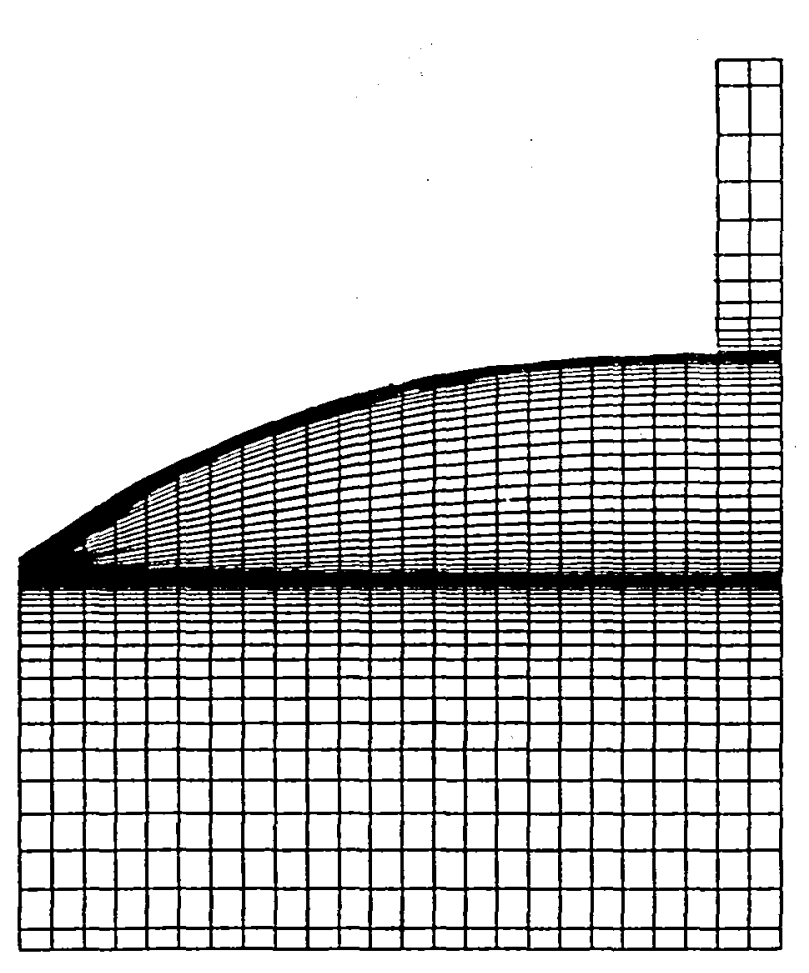

Figure 2. Typical Grid for Computation.

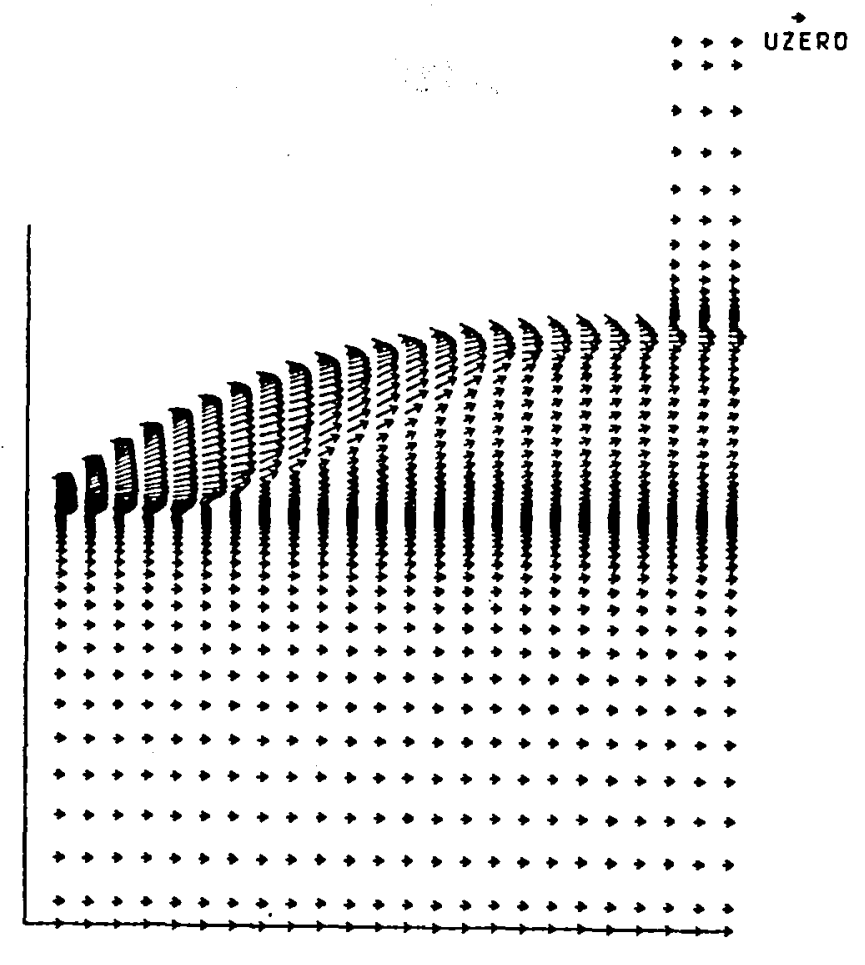

Figure 3. Mach 3, Velocity Vectors.

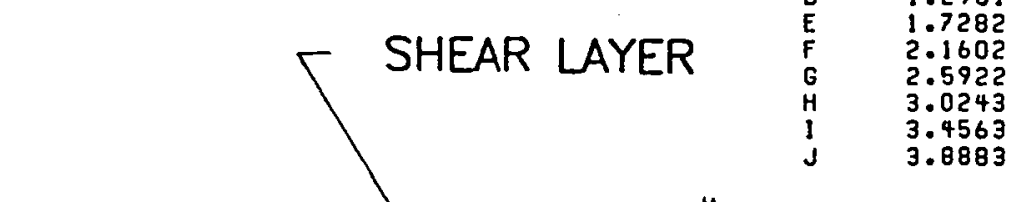

EXPANSION FAN

$\begin{array}{ll}A & 0.0000 \\ B & 0.4320 \\ C & 0.8641 \\ D & 1.2961 \\ E & 1.7282 \\ F & 2.1602 \\ G & 2.5922 \\ H & 3.0243 \\ \text { I } & 3.4563 \\ J & 3.8883\end{array}$

Figure 4. Mach 3, Mach Number Contours. 


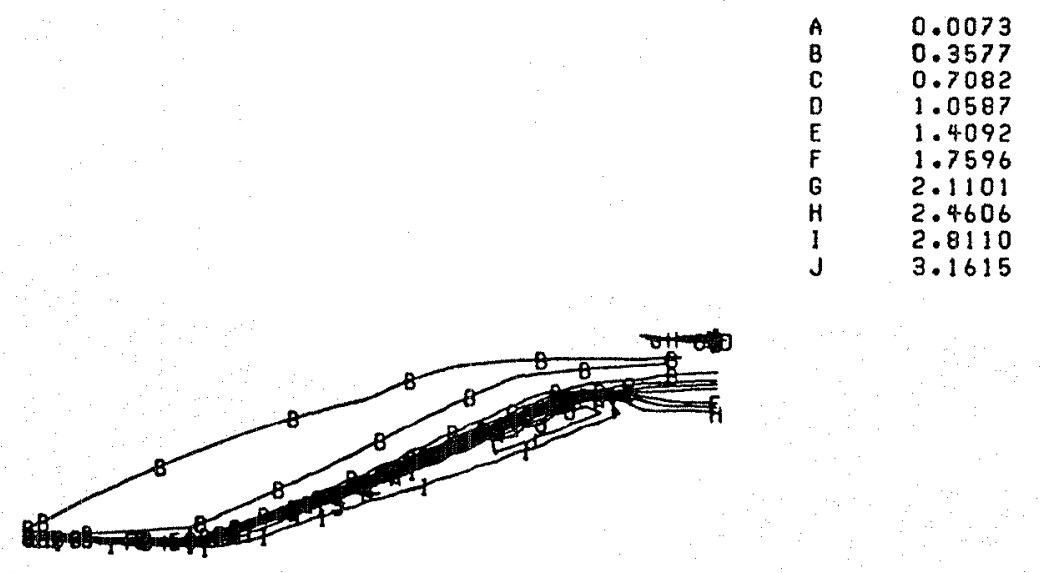

Figure 5. Mach 3, Total Pressure Contours.

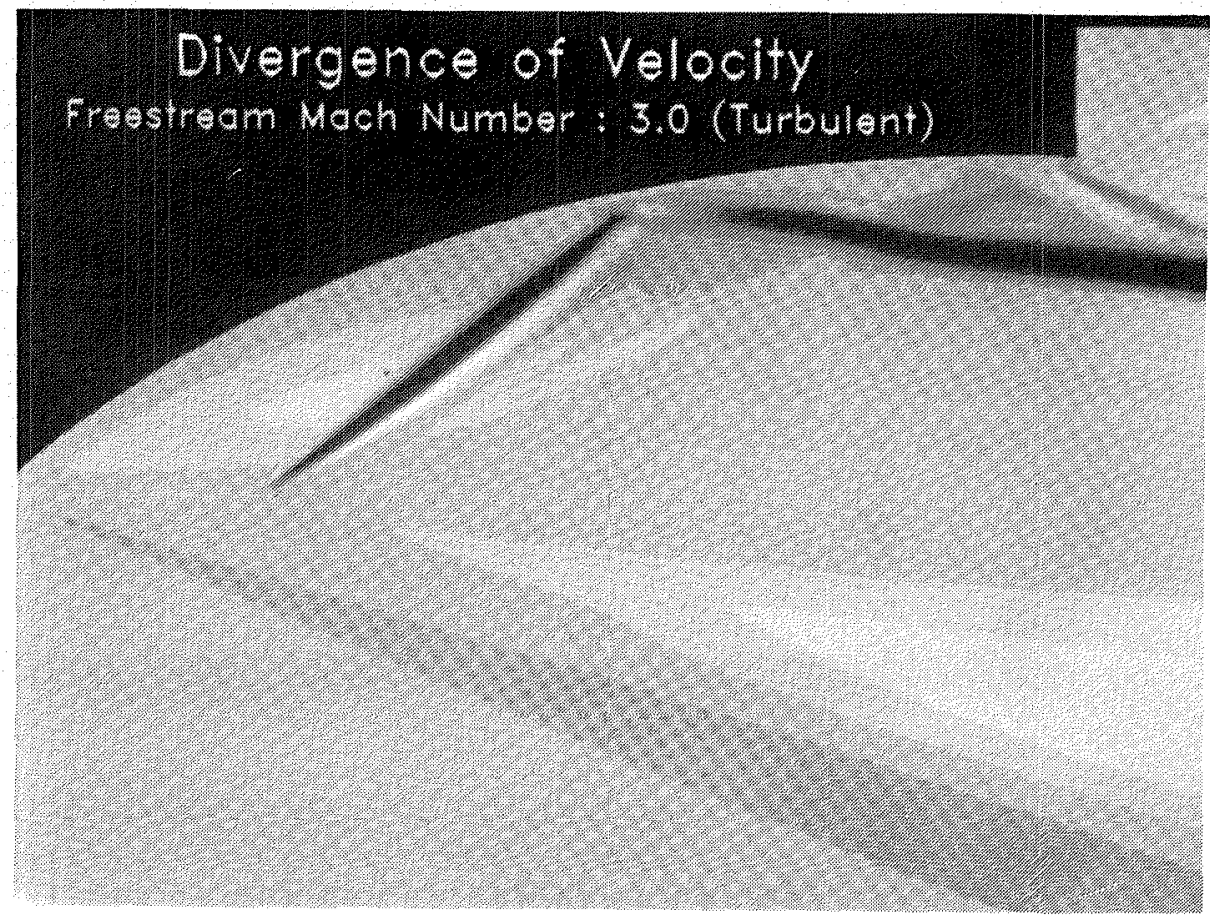

Figure 6. Mach 3, Divergence of Velocity. 

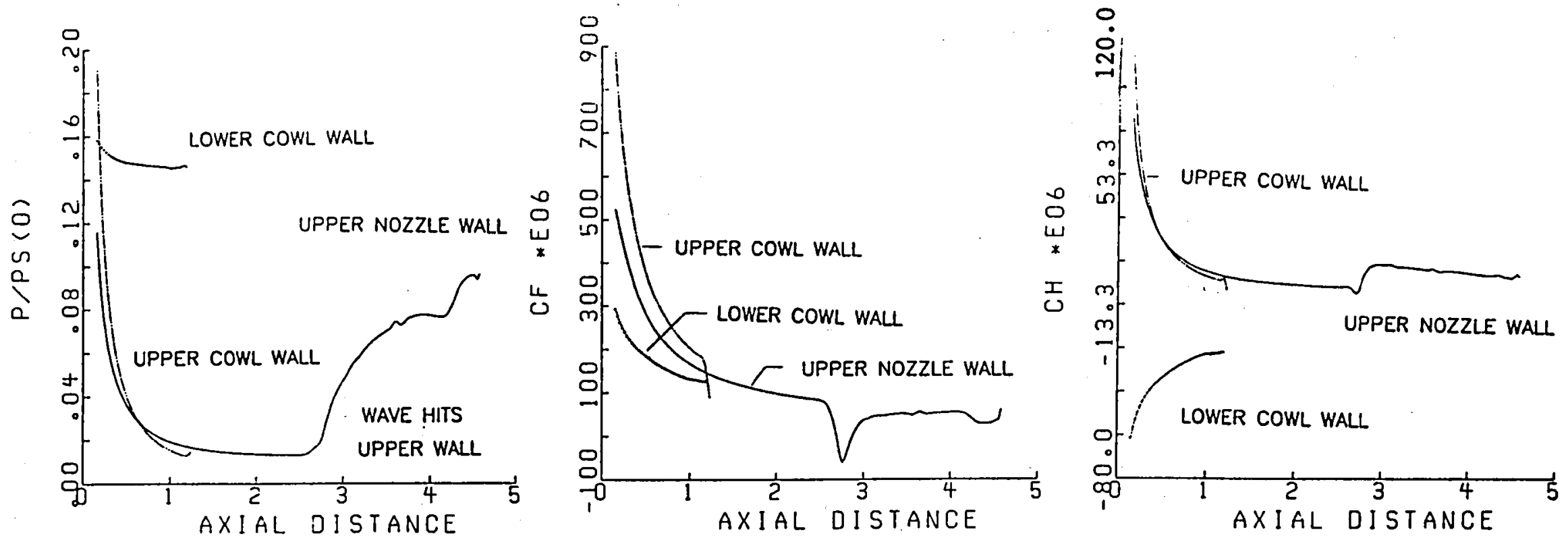

Figure 7. Mach $3, P_{w}, C_{f}, C_{h}$ vs. X. 


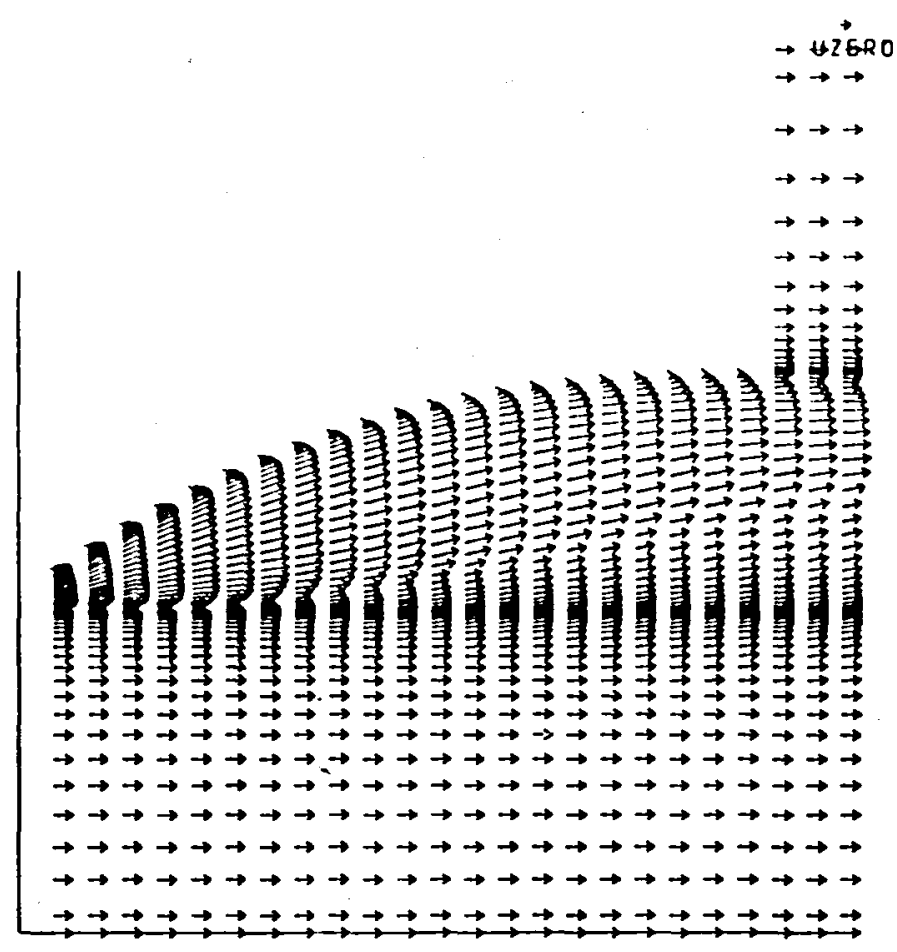

Figure 8. Mach 6, Velocity Vectors.

$\begin{array}{ll}\text { A } & 0.0000 \\ \text { B } & 0.7112 \\ \text { C } & 1.4223 \\ \text { D } & 2.1335 \\ \text { E } & 2.8446 \\ \text { F } & 3.5558 \\ G & 4.2670 \\ H & 4.9781 \\ \text { I } & 5.6893 \\ J & 6.4004\end{array}$

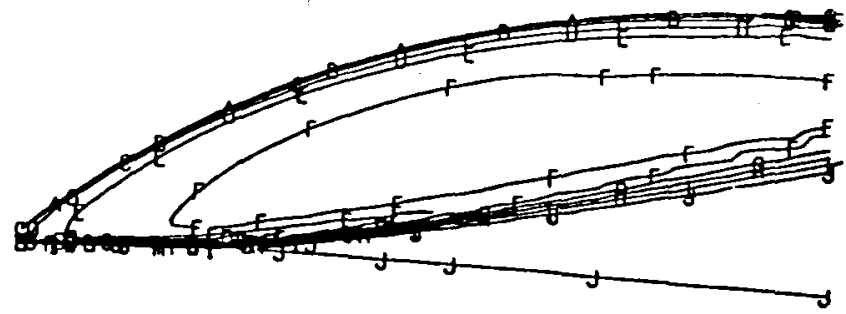

Figure 9. Mach 6, Mach Number Contours. 
0.0055

15.0583

30.1110

45.1637

60.2164

75.2691

90.3219

105.3746

120.4273

135.4801

$+1$

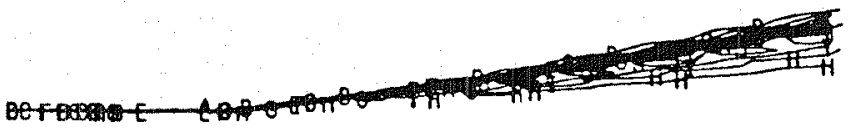

Figure 10. Mach 6, Total Pressure Contours.

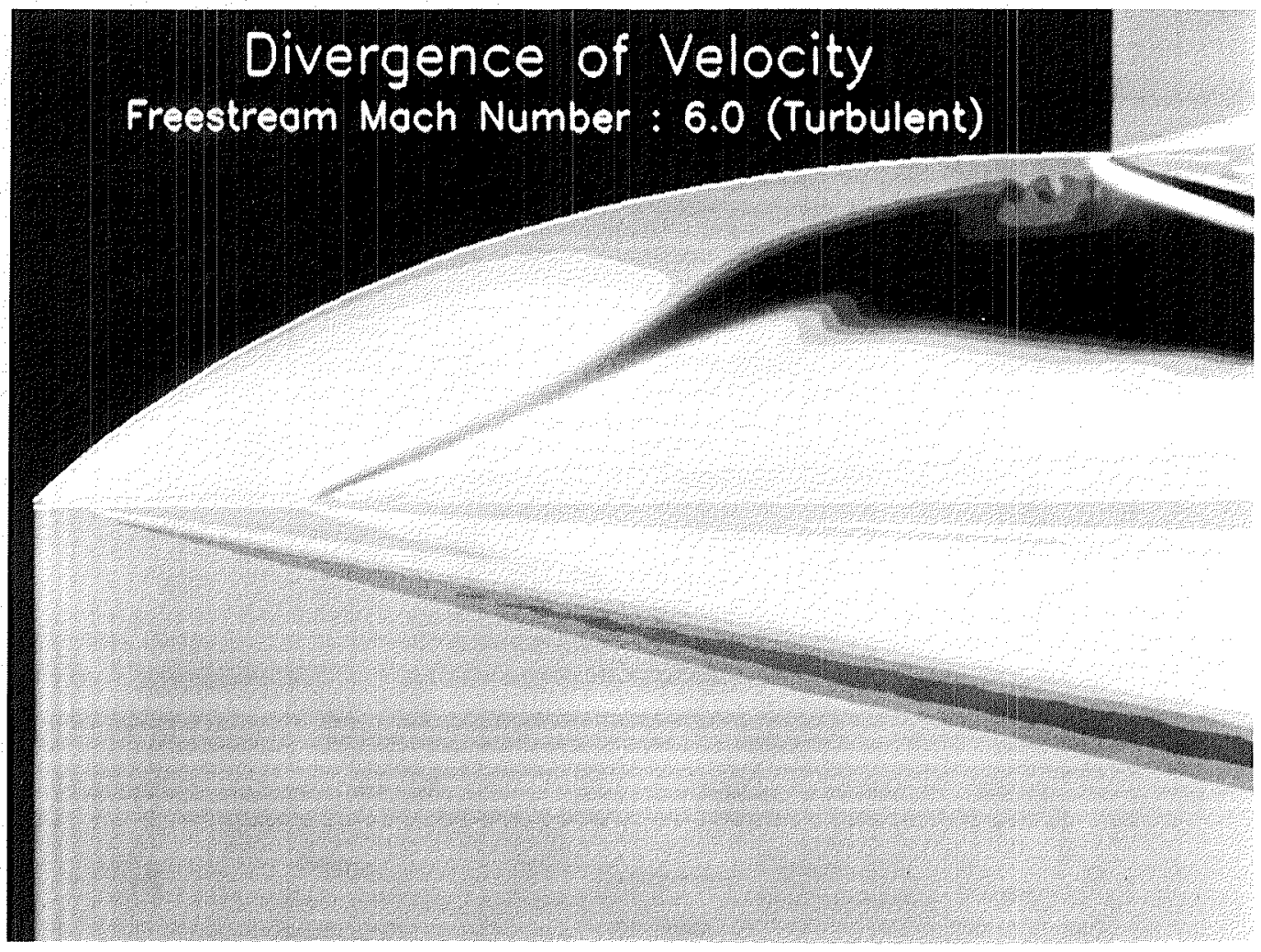

Figure 11. Mach 6, Divergence of Velocity. 

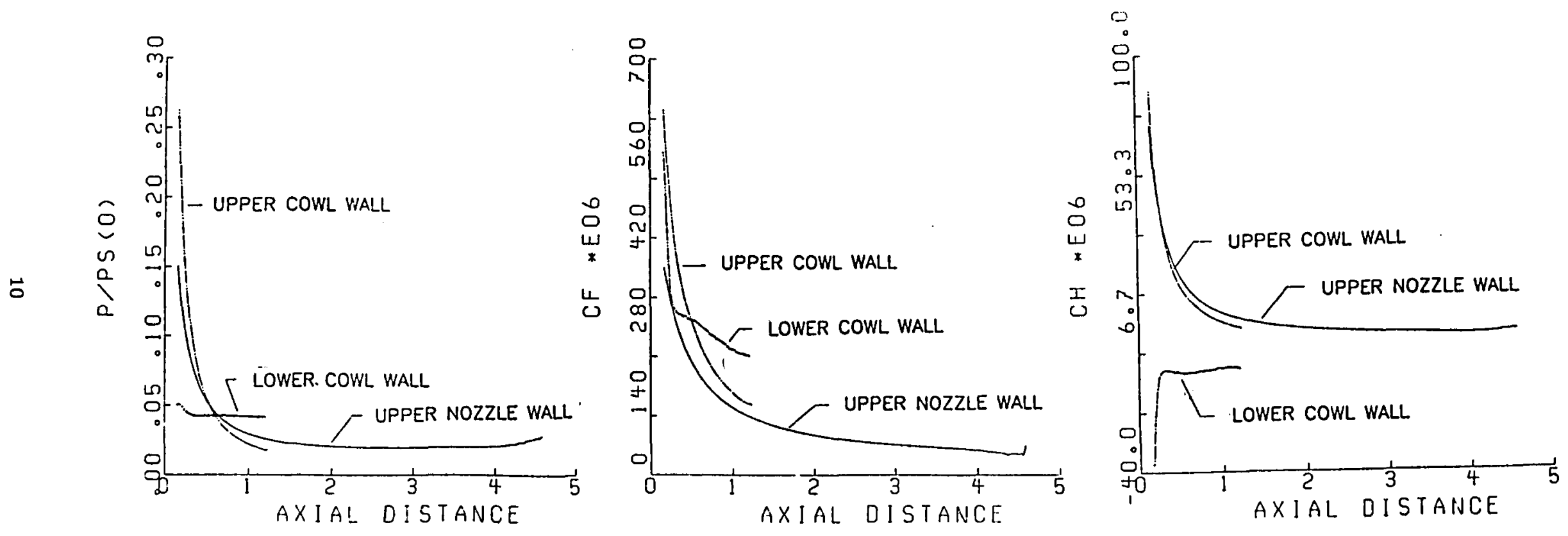

Figure 12. Mach 6, $P_{w}, C_{f}, C_{h}$ vs. X. 


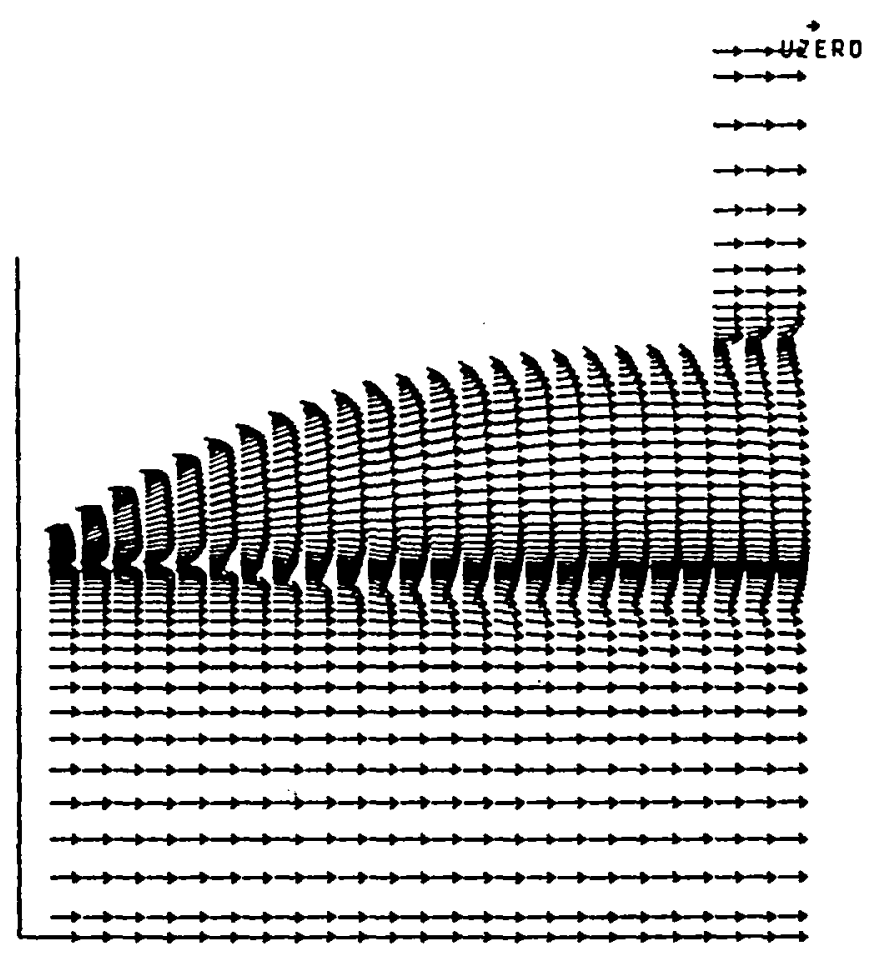

Figure 13. Mach 10, Velocity Vectors.

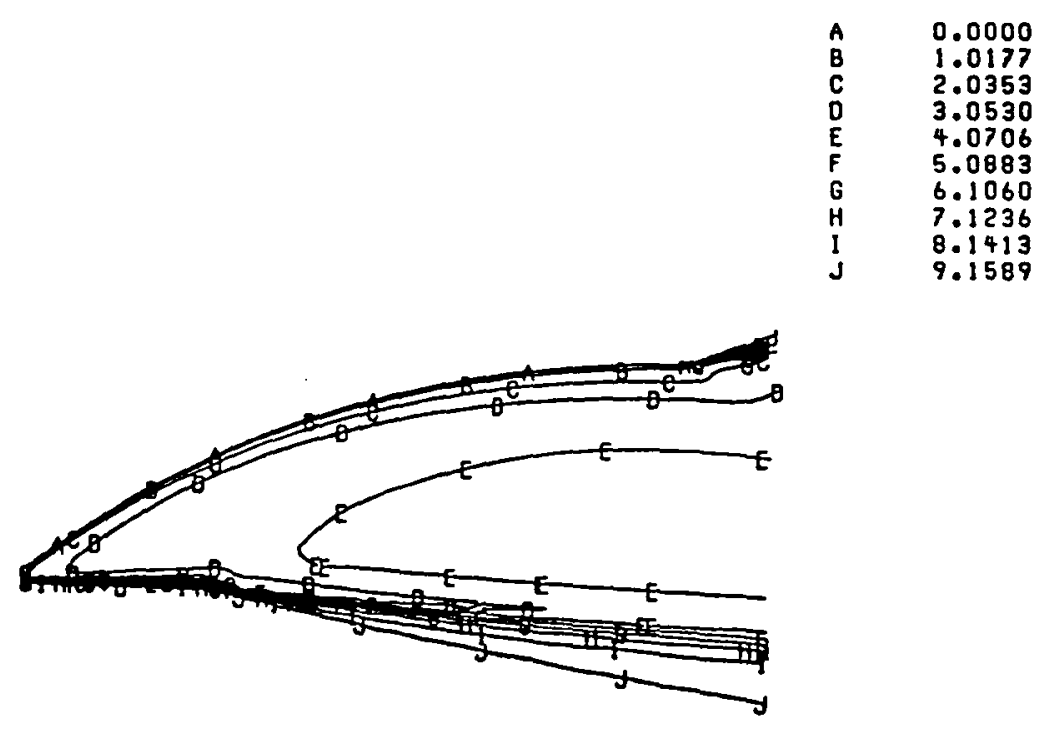

Figure 14. Mach 10, Mach Number Contours. 


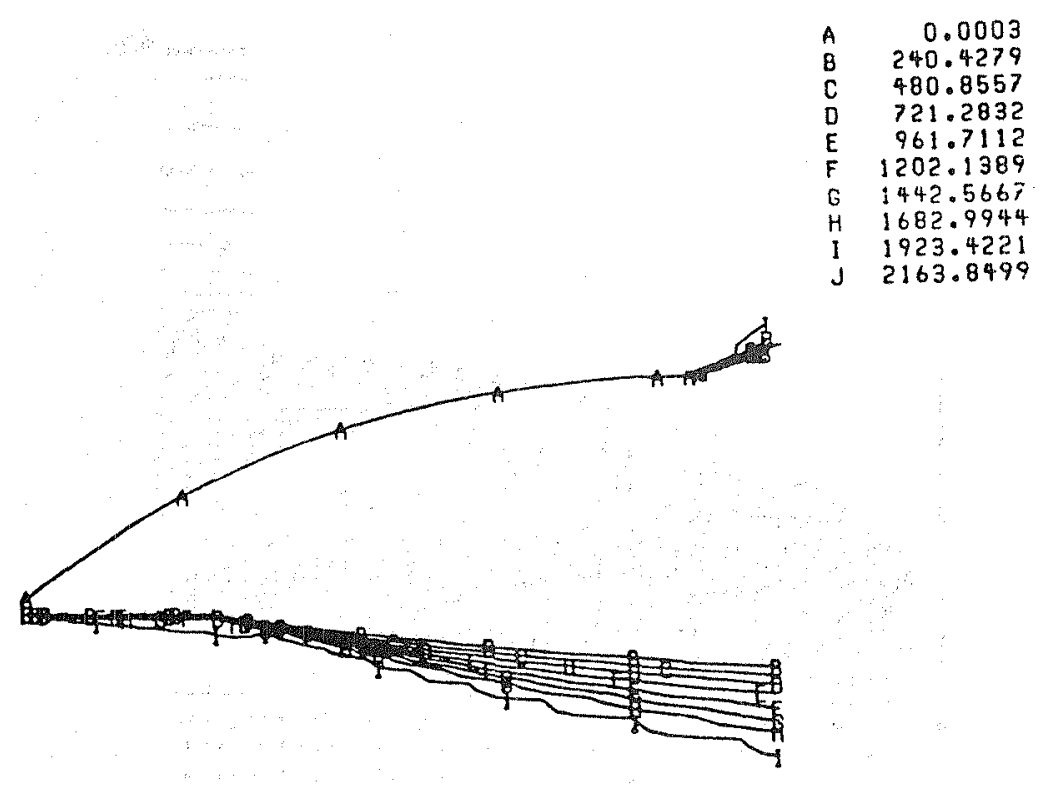

Figure 15. Mach 10, Total Pressure Contours.

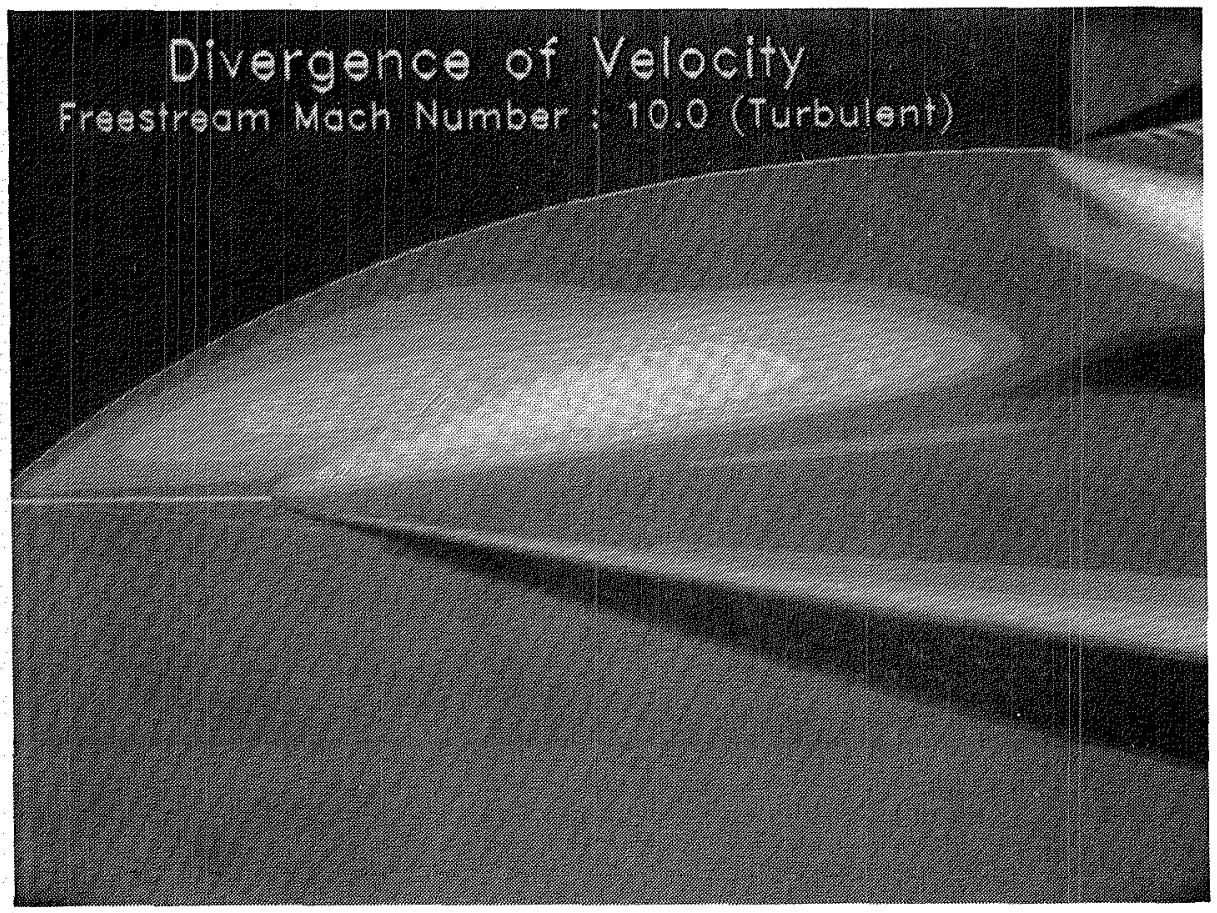

Figure 16. Mach 10, Divergence of Velocity. 

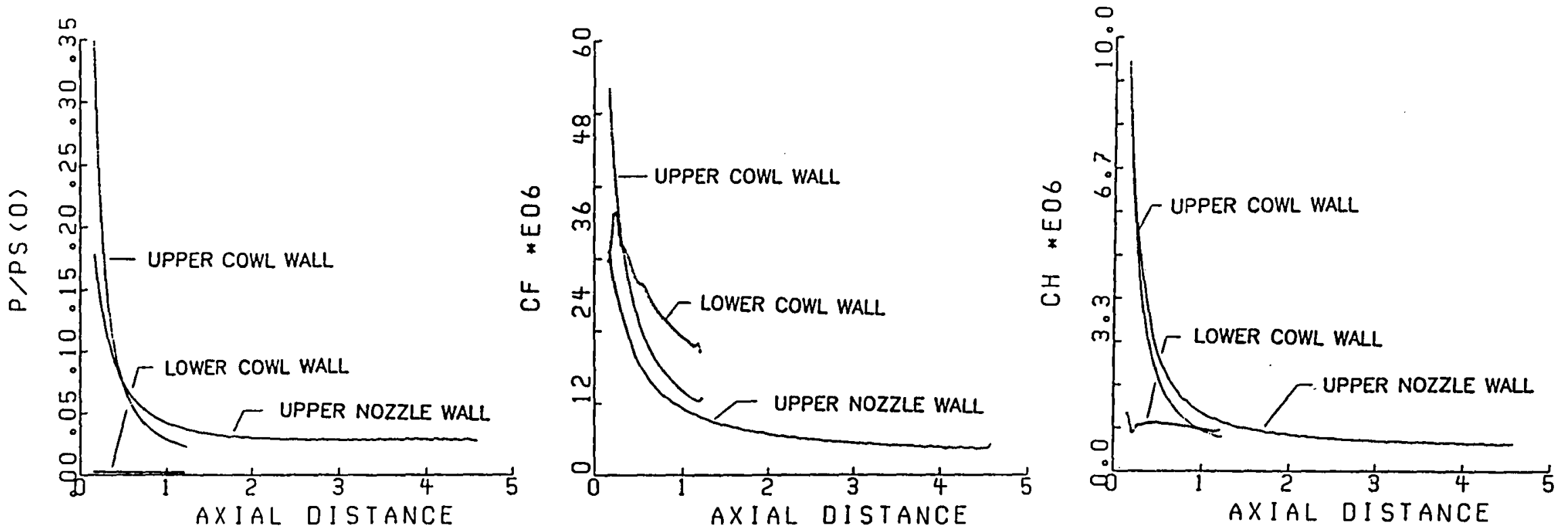

Figure 17. Mach 10, $P_{w}, C_{f}, C_{h}$ vs. X. 


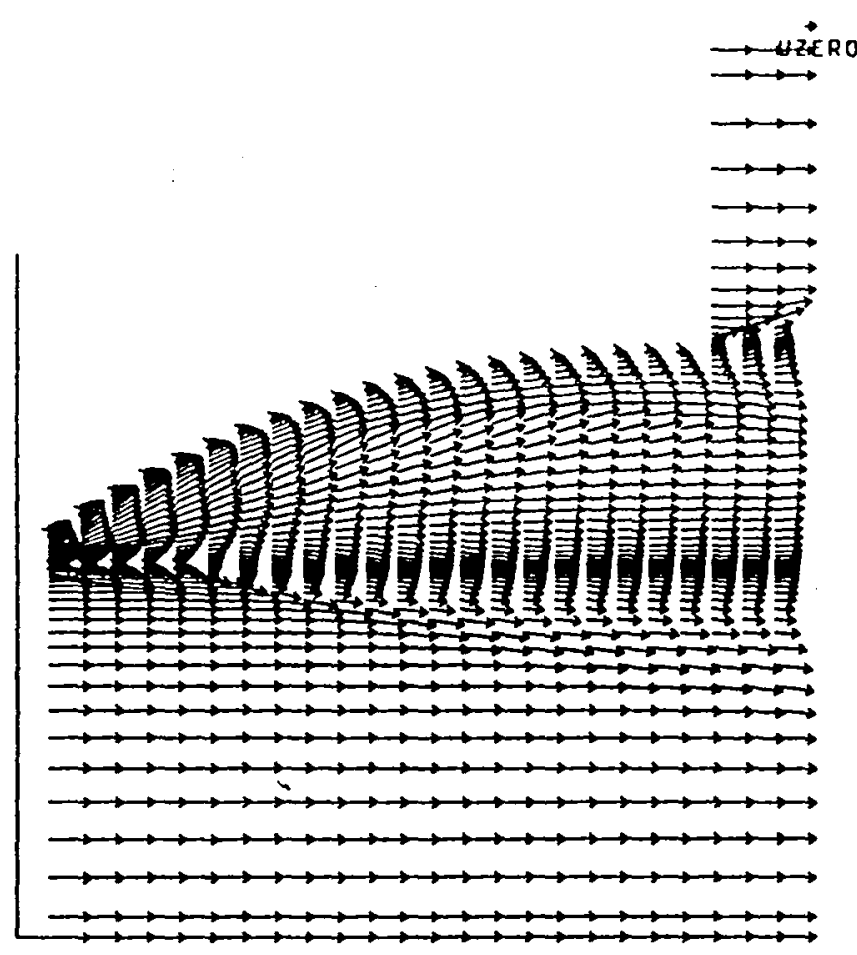

Figure 18. Mach 20, Velocity Vectors.

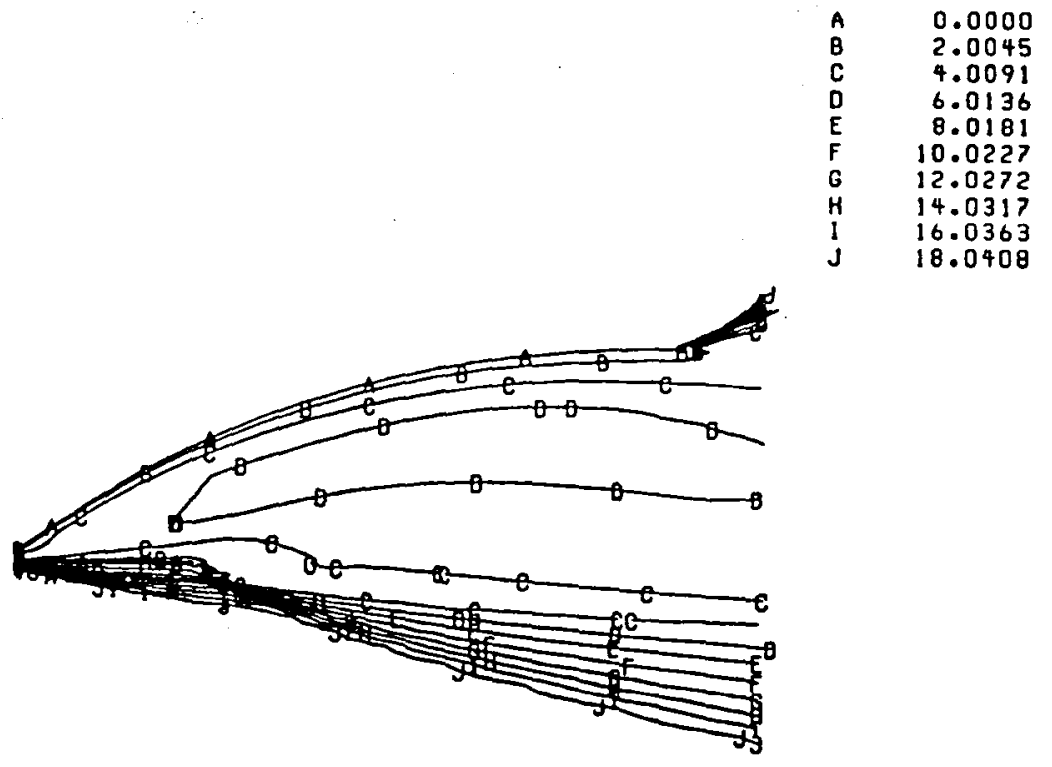

Figure 19. Mach 20, Mach Number Contours. 


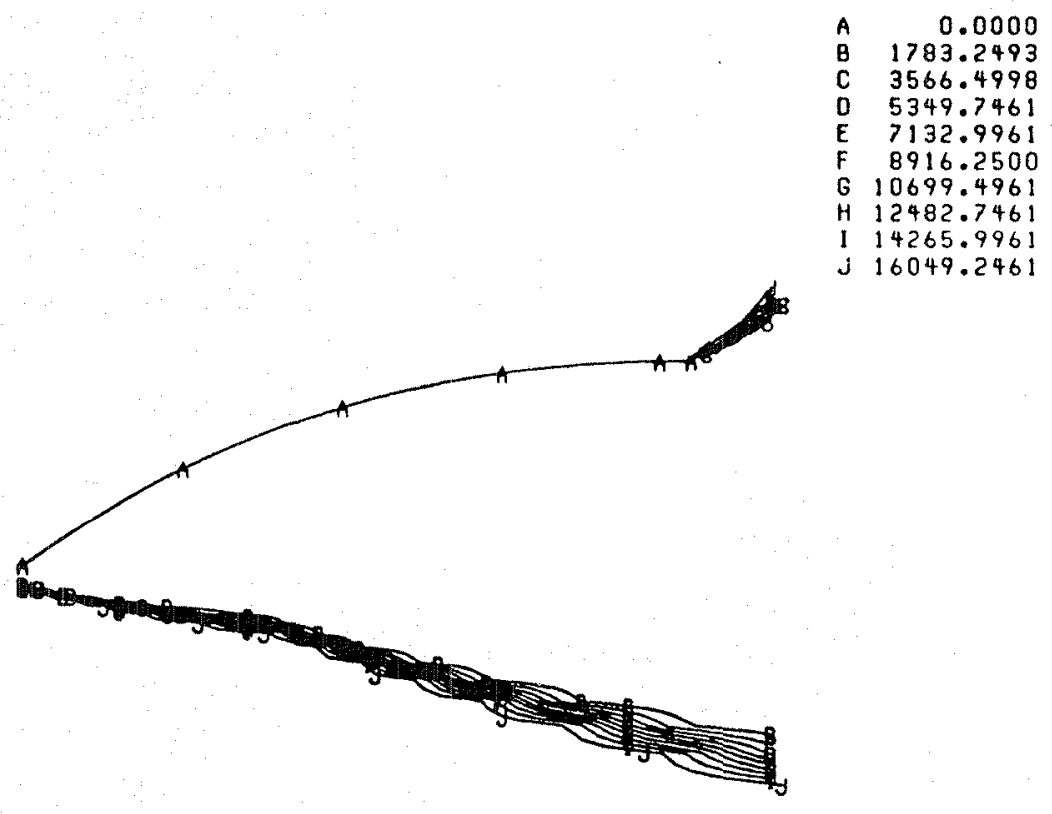

Figure 20. Mach 20, Total Pressure Contours.

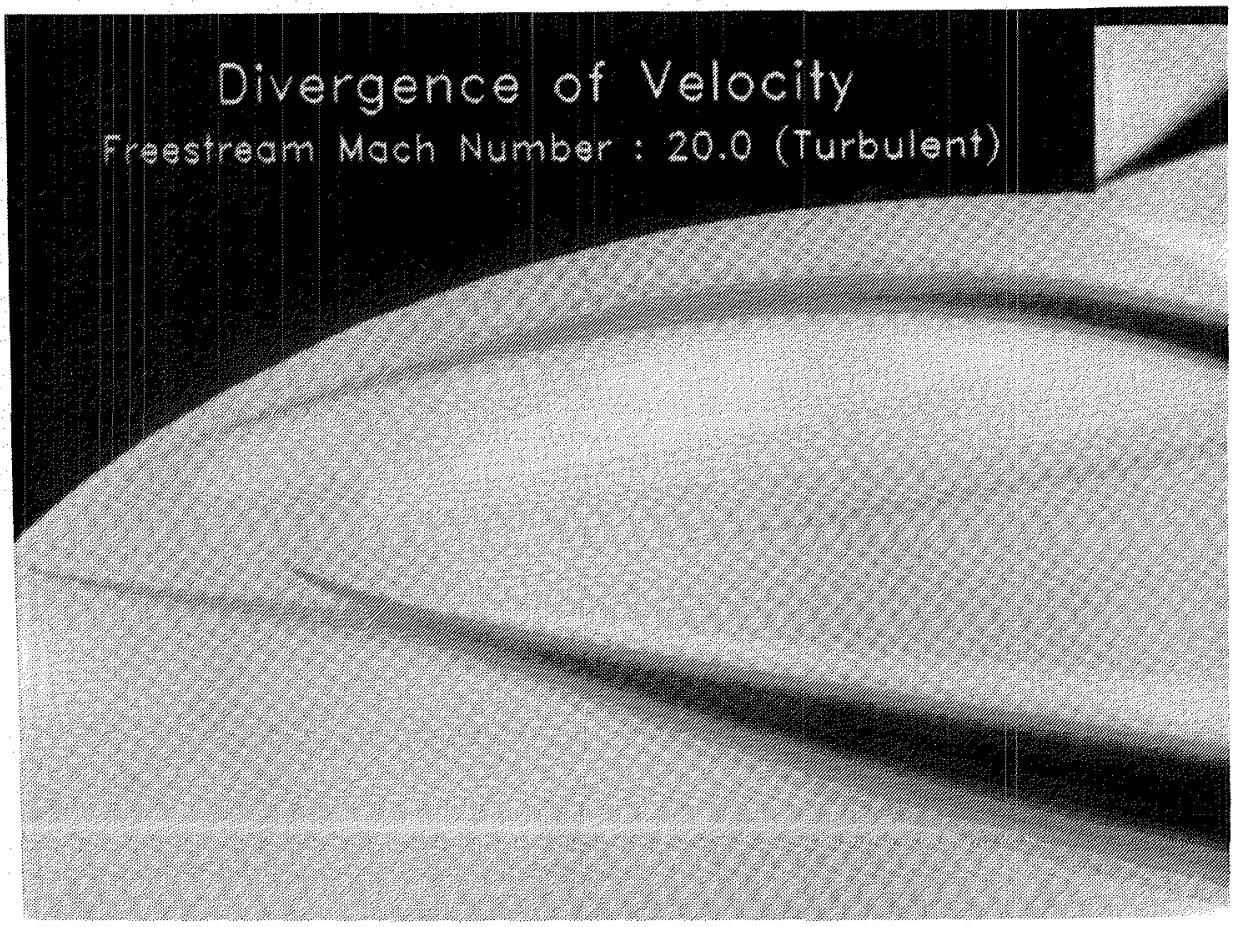

Figure 21. Mach 20, Divergence of Velocity. 


$$
H E=
$$




\begin{tabular}{|c|c|c|c|c|}
\hline \multicolumn{5}{|c|}{ Report Documentation Page } \\
\hline $\begin{array}{l}\text { 1. Report No. } \\
\text { NASA CR-182150 }\end{array}$ & \multicolumn{2}{|c|}{ 2. Government Accession No. } & \multicolumn{2}{|c|}{ 3. Recipient's Catalog No. } \\
\hline \multicolumn{3}{|c|}{$\begin{array}{l}\text { 4. Title and Subtitle } \\
\text { Two-Dimensional Viscous Flow Computations of } \\
\text { Hypersonic Scramjet Nozzle Flowfields at Design and } \\
\text { Off-Design Conditions }\end{array}$} & \multicolumn{2}{|c|}{$\begin{array}{l}\text { 5. Report Date } \\
\text { June } 19.88\end{array}$} \\
\hline \multirow{2}{*}{\multicolumn{3}{|c|}{$\begin{array}{l}\text { 7. Author(s) } \\
\text { G.J. Harloff, H.T. Lai, and E.S. Nelson }\end{array}$}} & \multicolumn{2}{|c|}{$\begin{array}{l}\text { 8. Performing Organization Report No. } \\
\text { None } \\
\text { (E-4190) }\end{array}$} \\
\hline & & & \multicolumn{2}{|c|}{$\begin{array}{r}\text { 10. Work Unit No. } \\
505-62-21\end{array}$} \\
\hline \multirow{2}{*}{\multicolumn{3}{|c|}{$\begin{array}{l}\text { 9. Performing Organization Name and Address } \\
\text { Sverdrup Technology, Inc. } \\
\text { (Lewis Research Center Group) } \\
\text { NASA Lewis Research Center } \\
\text { Cleveland, Ohio } 44135-3191\end{array}$}} & \multicolumn{2}{|c|}{$\begin{array}{l}\text { 11. Contract or Grant No. } \\
\text { NAS3-25266 } \\
\end{array}$} \\
\hline & & & \multicolumn{2}{|c|}{$\begin{array}{l}\text { 13. Type of Report and Period Covered } \\
\text { Contractor Report } \\
\text { Final }\end{array}$} \\
\hline \multicolumn{3}{|c|}{$\begin{array}{l}\text { 12. Sponsoring Agency Name and Address } \\
\text { National Aeronautics and Space Administration } \\
\text { Lewis Research Center } \\
\text { Cleveland, Ohio } 44135-3191\end{array}$} & \multicolumn{2}{|c|}{ 14. Sponsoring Agency Code } \\
\hline \multicolumn{5}{|c|}{$\begin{array}{l}\text { 15. Supplementary Notes } \\
\text { Project Manager, Peter M. Sockol, Internal Fluid Mechanics Division, NASA Lewis } \\
\text { Research Center. Prepared for the } 24 \text { th Joint Propulsion Conference cosponsored } \\
\text { by the AIAA, ASME, SAE, and ASEE, Boston, Massachusetts, July } 11-13,1988 .\end{array}$} \\
\hline \multicolumn{5}{|c|}{$\begin{array}{l}\text { 16. Abstract } \\
\text { The PARC2D code has been selected to analyze the flowfields of a representative } \\
\text { hypersonic scramjet nozzle over a range of flight conditions from Mach } 3 \text { to } 20 \text {. } \\
\text { The flowfields, wall pressures, wall skin friction values, heat transfer values } \\
\text { and overall nozzle performance are presented. }\end{array}$} \\
\hline \multicolumn{2}{|c|}{$\begin{array}{l}\text { 17. Key Words (Suggested by Author(s)) } \\
\text { Viscous flow Computations; 2-D; } \\
\text { Supersonic; Hypersonic; Nozzle }\end{array}$} & \multicolumn{3}{|c|}{$\begin{array}{l}\text { 18. Distribution Statement } \\
\text { Unclassified - Unlimited } \\
\text { Subject Category } 07\end{array}$} \\
\hline $\begin{array}{r}\text { 19. Security Classif. (of this rep } \\
\text { Unclass if }\end{array}$ & Security & sage) & $\begin{array}{c}\text { 21. No of pages } \\
18\end{array}$ & $\begin{array}{r}\text { 22. } \text { Price* }^{*} \\
\mathrm{AO2}\end{array}$ \\
\hline
\end{tabular}


End of Document 